\title{
ELABORAÇÃO E AVALIAÇÃO DAS CARACTERÍSTICAS FÍSICO- QUÍMICAS DE PÃES DE QUEIJO COM DIFERENTES BASES
}

\author{
Jéssica Taís Fell ${ }^{1}$, Luana Eliandra Seidel ${ }^{2}$, Hélder Conceição Pacheco ${ }^{3}$, \\ Grasciele Tamara Kemerich ${ }^{4}$, Eniz Conceição Oliveira ${ }^{5}$
}

Resumo: O pão de queijo é tradicionalmente mineiro, estando além das fronteiras de Minas Gerais, podendo ser encontrados diferentes tipos de pão de queijo no mercado. $\mathrm{O}$ trabalho teve como objetivo avaliar as características físico-químicas de pães de queijo formulados com diferentes bases, bem como a determinação de sua aceitabilidade por meio da análise sensorial e intenção de compra. A pesquisa foi realizada na Universidade do Vale do Taquari - Univates, situada no município de Lajeado/RS. As análises de aceitabilidade foram realizadas por um grupo de 49 provadores não treinados, e as análises físico-químicas foram realizadas em triplicata, onde foram encontrados valores em percentual, de carboidratos entre $28,84 \%$ e $31,44 \%$, cinzas $1,12 \%$ e $1,54 \%$, lipídeos $6,68 \%$ e $8,84 \%$ e proteínas entre, $2,79 \%$ e $3,57 \%$. Os pães de queijo elaborados com diferentes bases, não puderam ser comparados com outras formulações, pois não existe um padrão de identidade e qualidade específico para o produto.

Palavra-chave: pão de queijo, batata-doce, batata-inglesa, mandioca, aceitabilidade.

1 Graduanda em Química Industrial pela Universidade do Vale do Taquari - Univates. Lajeado, RS, Brasil. E-mail: jessica.fell@hotmail.com

2 Graduanda em Química Industrial pela Universidade do Vale do Taquari - Univates. Lajeado, RS, Brasil. E-mail: luana_eliandra@hotmail.com

3 Graduando em Química Industrial pela Universidade do Vale do Taquari - Univates. Lajeado, RS, Brasil. E-mail: helder@universo.univates.br

4 Mestranda do Programa de Pós-Graduação em Biotecnologia da Universidade do Vale do Taquari - UNIVATES.

5 Doutorado na Universidade Federal do Rio Grande do Sul - Professora titular na Universidade do Vale do Taquari - UNIVATES. 


\section{INTRODUÇÃO}

Tradicionalmente mineiro, o pão de queijo pode ser obtido através da mistura de polvilho, água ou leite, queijo, sal e gordura (PEREIRA et al., 2004). Além de ser fonte de carboidrato, é isento de glúten, assim podendo ser consumido por pacientes alérgicos às proteínas do trigo (PEREIRA et al., 2004). A fabricação do pão de queijo foi além das fronteiras de Minas Gerais, e do país, onde foi surgindo vários fabricantes (INMETRO, 2017). Segundo Pereira et al. (2005) podem ser encontrados diferentes tipos de pão de queijo no mercado, contudo, esta variação tem uma justificativa, pois para o produto pronto não existe um padrão de qualidade e identidade.

O produto pode ser apresentado já modelado e congelado, em pó para posterior adição de ingredientes ou ainda na forma de massa congelada (MINIM, 2000). Segundo Tomich et al. (2005) existem atualmente mais de 500 indústrias de pão de queijo no Brasil, maior parte no estado de Minas Gerais. Conforme Silva (2009) o pão de queijo não possui uma formulação exata, tão pouco um padrão de ingredientes, constituindo-se num produto versátil no qual é possível uma variedade de ingredientes para diferentes objetivos. Sendo possível desenvolver formulações para públicos específicos, empregando matérias-primas disponíveis na região (SILVA, 2009).

Existem diversos tipos de queijo que podem ser utilizados na elaboração do pão de queijo, os mais comuns são mozarela, parmesão, minas e lanche, que contribuem no aroma e sabor, que são característicos do produto. $\mathrm{O}$ queijo auxilia na textura do miolo, dando a elasticidade característica do produto. Utiliza-se preferencialmente o polvilho azedo ao doce, pois confere ao produto maior volume, porosidade e esponjosidade ao miolo. O óleo de soja utilizado é o comum, mas pode ser usado azeite para dar características específicas e acentuar o sabor, pode-se usar gordura desidrogenada (PEREIRA et al., 2005).

A batata-doce é uma das hortaliças mais produzidas no Brasil, ocupando o $6^{\circ}$ lugar no ranking (EMBRAPA, 2008). A batata-doce tem a desvantagem de ser um produto perecível, devendo ser utilizada em poucos dias após a colheita. Todavia, por ser uma tuberosa e podendo ser usada pelas indústrias de amido brasileiras, contribuiria para o avanço tecnológico da cultura (LEONEL, 2007). A mandioca, também conhecida como macaxeira ou aipim, faz parte do grupo das raízes e tubérculos (FUSIEGER, 2017). É um dos principais alimentos energéticos, sendo um alimento de fácil adaptação, situa-se entre os oito primeiros produtos agrícolas do país e cultivada em todos os estados brasileiros (MATTOS; FARIAS; FILHO, 2006). Os benefícios da mandioca são: fonte de carboidratos, vitamina C, cálcio e fósforo (FUSIEGER, 2017). A batata inglesa é fonte de fósforo, vitamina C e vitaminas do grupo B (NUNES, 1996). Para os diabéticos são indicados os tubérculos como batata inglesa, batata-doce, que são fontes de carboidratos (FUSIEGER, 2017). 
O pão de queijo normalmente é associado à presença de leite, tanto como seu derivado o queijo, todavia na atualidade há uma maior preocupação e atenção a grupos de consumidores com necessidades de consumo específicas (RAMALHO, 2016). Sendo a intolerância a lactose uma delas, assim torna-se comum encontrar produtos finais e matérias-primas desenvolvidas tendo estes consumidores como público alvo (RAMALHO, 2016).

O objetivo deste trabalho foi avaliar as características físico-químicas de pães de queijo formulados com diferentes bases, bem como a determinação de sua aceitabilidade por meio da análise sensorial e intenção de compra.

\section{METODOLOGIA}

\subsection{Material e Métodos}

Os ingredientes utilizados para a produção do pão de queijo foram adquiridos no comércio local sendo: a batata inglesa, batata doce, mandioca, polvilho azedo, queijo sem lactose, ovos, sal, óleo de soja, azeite de oliva, salame tipo italiano, orégano, semente de chia e gergelim.

\subsection{Elaboração do pão de queijo}

Foram preparadas três formulações de pães de queijo onde se alterou apenas um dos ingredientes base como batata inglesa, batata doce e mandioca, conforme proporções descritas no Quadro 1.

Quadro 1 - Quantidade dos ingredientes das formulações de pão de queijo

\begin{tabular}{|l|c|c|c|}
\hline \multirow{2}{*}{\multicolumn{1}{|c|}{ Ingredientes (\%) }} & \multicolumn{3}{|c|}{ Formulação } \\
\cline { 2 - 4 } Mandioca & A & B & C \\
\hline Batata inglesa & ---- & 52,72 & ---- \\
\hline Batata doce & 52,00 & ---- & ---- \\
\hline Polvilho azedo & ----- & ---- & 42,43 \\
\hline Água & 22,07 & 21,74 & 26,47 \\
\hline Queijo sem lactose & 7,56 & 7,45 & 9,07 \\
\hline Salame tipo italiano & 6,13 & 6,04 & 7,35 \\
\hline Ovo & 3,98 & 3,92 & 4,77 \\
\hline Óleo de soja & 3,33 & 3,28 & 3,99 \\
\hline Semente de gergelim & 2,42 & 2,38 & 2,90 \\
\hline Semente de chia & 0,89 & 0,88 & 1,07 \\
\hline
\end{tabular}




\begin{tabular}{|l|c|c|c|}
\hline \multirow{2}{*}{ Ingredientes (\%) } & \multicolumn{3}{|c|}{ Formulação } \\
\cline { 2 - 4 } & $\mathbf{A}$ & $\mathbf{B}$ & $\mathbf{C}$ \\
\hline Sal & 0,60 & 0,60 & 0,73 \\
\hline Azeite de oliva & 0,30 & 0,30 & 0,36 \\
\hline Orégano & 0,08 & 0,08 & 0,09 \\
\hline
\end{tabular}

Fonte: Dos autores (2017).

Para a preparação do pão de queijo foram seguidas as etapas apresentadas na Figura 1.

Figura 1 - Fluxograma da fabricação do pão de queijo

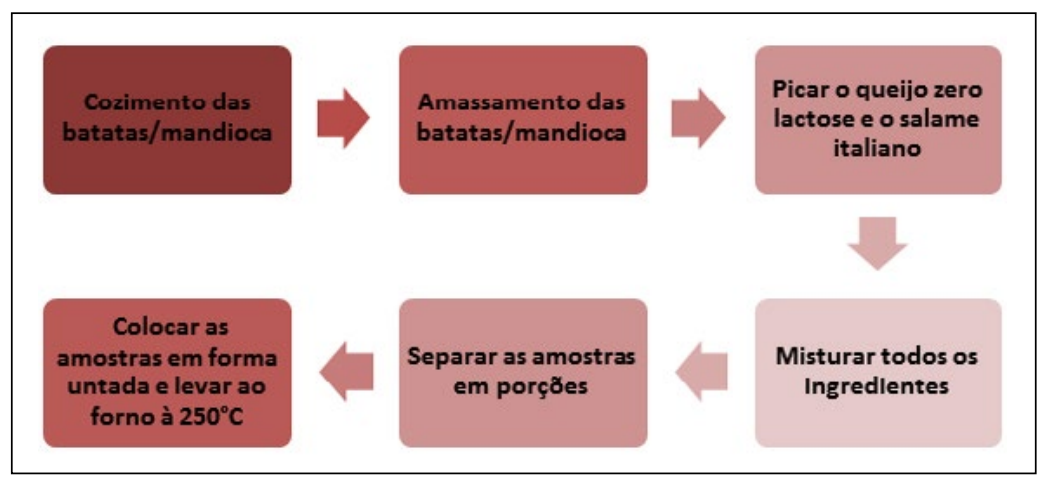

Fonte: Dos autores (2017).

Os pães de queijo foram produzidos no Laboratório de Cárneos e Lácteos (Universidade do Vale do Taquari - Univates), realizando três formulações com diferentes bases. Pesaram-se as bases separadamente (860 g batata inglesa, $885 \mathrm{~g}$ mandioca e $585 \mathrm{~g}$ batata doce), amassou-se manualmente em bandejas individuais com auxílio de garfo. Acrescentou-se um ovo (equivalente a $55 \mathrm{~g}$ ), $5 \mathrm{~g}$ de azeite de oliva, $40 \mathrm{~g}$ de óleo de soja e água, sendo $125 \mathrm{~g}$ de água na batata inglesa, $150 \mathrm{~g}$ na mandioca e $150 \mathrm{~g}$ na batata doce, misturando todos os ingredientes. Após acrescentou-se $365 \mathrm{~g}$ de polvilho azedo, 1,30 g de orégano, $10,80 \mathrm{~g}$ de semente de gergelim, 10,44 g de semente de chia, homogeneizou-se e em seguida adicionou-se 101,40 g de queijo sem lactose, 65,75 g de salame italiano e por último $10 \mathrm{~g}$ de sal fino, misturando até obter-se uma massa homogênea. Deu-se forma ao produto e colocou-as em uma assadeira untada. Assou-se em forno pré-aquecido a $250^{\circ} \mathrm{C}$ por 30 minutos ou até ficar dourado.

\subsection{Determinações físico-químicas}

A composição centesimal foi determinada utilizando-se os procedimentos descritos pelo Instituto Adolfo Lutz (2008), onde o nitrogênio 
foi dosado empregando-se método Kjeldahl e convertido em proteína bruta pelo fator 6,25. Os lipídios foram analisados usando-se hidrólise ácida e a técnica soxhlet, a umidade foi feita em estufa a $105^{\circ} \mathrm{C}$ (marca Deleo, modelo A6AFD) e as cinzas foram determinadas pelo método de incineração em mufla a $550^{\circ} \mathrm{C}$ (mara Marconi, modelo MA 385/2). O pH foi determinado pelo método potenciométrico (pHmetro Digimed, modelo DM 22) e atividade de água pelo Aqualab- Lite (Decagon). A determinação dos carboidratos foi feita por diferença entre $100 \mathrm{~g}$ de amostra e a soma total dos valores encontrados para proteínas, lipídios, cinzas e umidade. Todas as análises químicas foram realizadas em duplicata.

\subsection{Análise sensorial}

As amostras foram codificadas com números de três dígitos e servidas aos provadores junto com a ficha do teste contendo uma escala hedônica de 1 a 9, sendo o 1 "desgostei muitíssimo" e 9 "gostei muitíssimo", avaliando os aspectos de aparência, sabor, odor, textura e impressão global. A análise sensorial, através do teste de aceitação, foi realizada por 49 provadores de ambos os sexos, entre eles alunos e professores da Universidade do Vale do Taquari - Univates. Outro aspecto que foi avaliado foi a intenção de compra dos produtos, variando de 1 "certamente compraria" a 5 "certamente não compraria". Para o cálculo de Índice de Aceitabilidade (IA), foi adotada a expressão IA $(\%)=\mathrm{A} \times 100 / \mathrm{B}$, em que, $\mathrm{A}=$ nota média obtida para o produto e $\mathrm{B}=$ nota máxima dada ao produto.

\section{RESULTADOS E DISCUSSÃO}

A Tabela 2 apresenta os resultados das análises físico-químicas e seu respectivo desvio padrão das formulações de pães de queijo elaborados com batata inglesa (Formulação A), mandioca ( Formulação B) ou com adição de batata doce ( Formulação C).

Tabela 2 - Resultados das análises físico-químicas realizadas na massa de pão de queijo

\begin{tabular}{l|c|c|c}
\hline \multirow{2}{*}{\multicolumn{1}{c|}{ Análises }} & \multicolumn{3}{|c}{ Formulação } \\
\cline { 2 - 4 } & A & B & C \\
\hline Atividade de água & $0,92 \pm 5^{*} 10^{-4}$ & $0,92 \pm 4^{*} 10^{-3}$ & $0,92 \pm 1^{*} 10^{-3}$ \\
\hline Carboidratos (\%) & $28,84 \pm 0,35$ & $31,44 \pm 1,23$ & $29,11 \pm 0,67$ \\
\hline Cinzas (\%) & $1,35 \pm 0,02$ & $1,12 \pm 0,01$ & $1,54 \pm 0,01$ \\
\hline Lipídios (\%) & $6,68 \pm 0,39$ & $7,52 \pm 0,62$ & $8,84 \pm 0,25$ \\
\hline Proteínas (\%) & $3,46 \pm 0,14$ & $2,79 \pm 0,03$ & $3,57 \pm 0,19$ \\
\hline pH & $5,17 \pm 0,02$ & $5,15 \pm 0,01$ & $5,22 \pm 0,02$ \\
\hline Umidade (\%) & $59,67 \pm 0,63$ & $57,13 \pm 0,60$ & $56,94 \pm 0,63$ \\
\hline
\end{tabular}

Fonte: Dos autores (2017). 
A atividade de água (aw) influência no tempo de prateleira, pois quanto mais alto for aw, maior a velocidade de reação, ou seja, para a maioria dos alimentos secos, um aumento de 0,1 na aw, diminui de 2 a 3 vezes o tempo de prateleira (SHIBATA, 2017). A análise de atividade de água tem como intuito quantificar a quantia de água livre disponível na formulação do pão de queijo, a análise de carboidratos tem como intuito de quantificar sacarídeos presentes. Pode-se observar que não houve diferença nas análises de atividade de água entre as formulações, este valor obtido pode influenciar diretamente no tempo de prateleira, segundo Shibata (2017).

A análise de cinzas é utilizada para determinar as quantidades de minerais, os mesmos podem ter valor nutricional na dieta humana. Os lipídios são majoritariamente gorduras, as proteínas são constituídas aminoácidos. A determinação de $\mathrm{pH}$ demonstra o teor de acidez do alimento, sendo quanto menor o valor, mais ácido. A análise de umidade ajuda a determinar a durabilidade e outras características sensoriais dos alimentos.

Os pães de queijo elaborados com diferentes bases não puderam ser comparados com outras formulações, pois não existe um padrão de identidade e qualidade específico para o produto, assim possuindo uma grande variedade de formulações. Observou-se que as formulações contendo batata doce e batata inglesa, obtiveram um valor aproximado na análise de proteínas, isso pode ter ocorrido pelas batatas pertencerem à mesma família de hortaliças.

Conforme exposto na Tabela 2, foi encontrado um valor mais elevado de carboidratos para formulação B, 31,44\% seguida pelas formulações C e A. Quanto a análise de lipídeos a formulação C obteve o maior percentual, 8,84\% seguida das formulações B e A. Quanto aos os valores obtidos de cinzas a formulação C apresentou o maior resultado 1,54\%, seguido de A e B.

As notas obtidas na análise sensorial, quanto à preferência, utilizando a escala hedônica, para pães de queijos elaborados com diferentes bases, podem ser observadas na Figura 2. 
Figura 2 - Aceitabilidade das formulações de pães de queijo

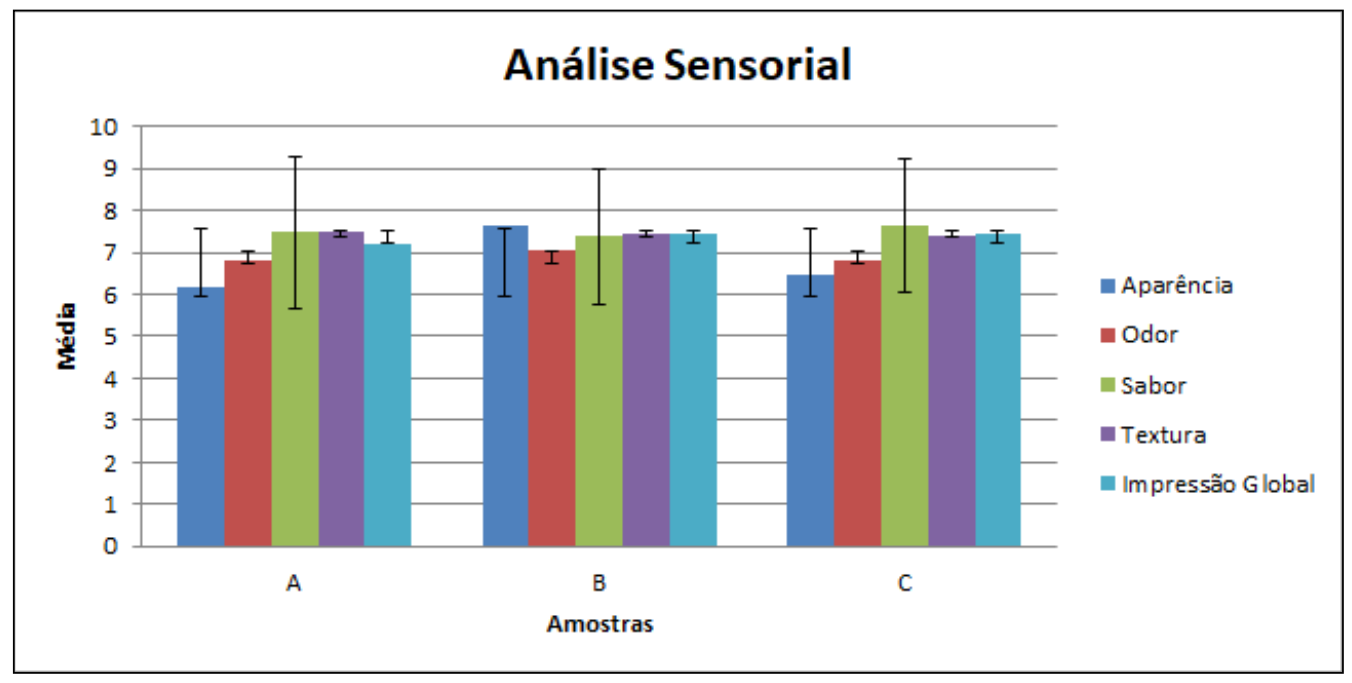

Fonte: Dos autores (2017).

Pode-se verificar que no quesito sabor, textura e impressão global as amostras obtiveram notas entre 7 e 8 , ou seja, pode-se observar boa aceitabilidade dos pães de queijo nas três formulações com diferentes bases. No geral os resultados foram semelhantes para as formulações. Deve ser levada em conta a quantidade de ingredientes utilizados, 12 para cada formulação, sendo que há a modificação de apenas 1 ingrediente para os três tipos de pão de queijo e a padronização do processo de produção.

As amostras apresentaram semelhanças entre si, 11 ingredientes em comum e em quantidades muito semelhantes como demonstrado anteriormente, sendo a maior variação quanto à aceitabilidade associada a um gosto pessoal dos provadores em relação suas preferências de acordo com a matéria-prima base, não sendo considerada falha nenhuma das três receitas testadas. Todavia seriam necessárias mais análises quanto à comercialização das amostras para a elaboração de um plano de negócios, com análises de custos de produção e viabilidade.

A intenção de compra dos provadores para os três tipos de pães de queijo foi analisada conforme mostra a Figura 3. A amostra melhor classificada na opção, certamente compraria foi a amostra C, seguida de A e B respectivamente. Para as três formulações as opções mais escolhidas pelos provadores foram, certamente compraria, e possivelmente compraria. 
Figura 3 - Intenção de compra das três formulações de pães de queijo

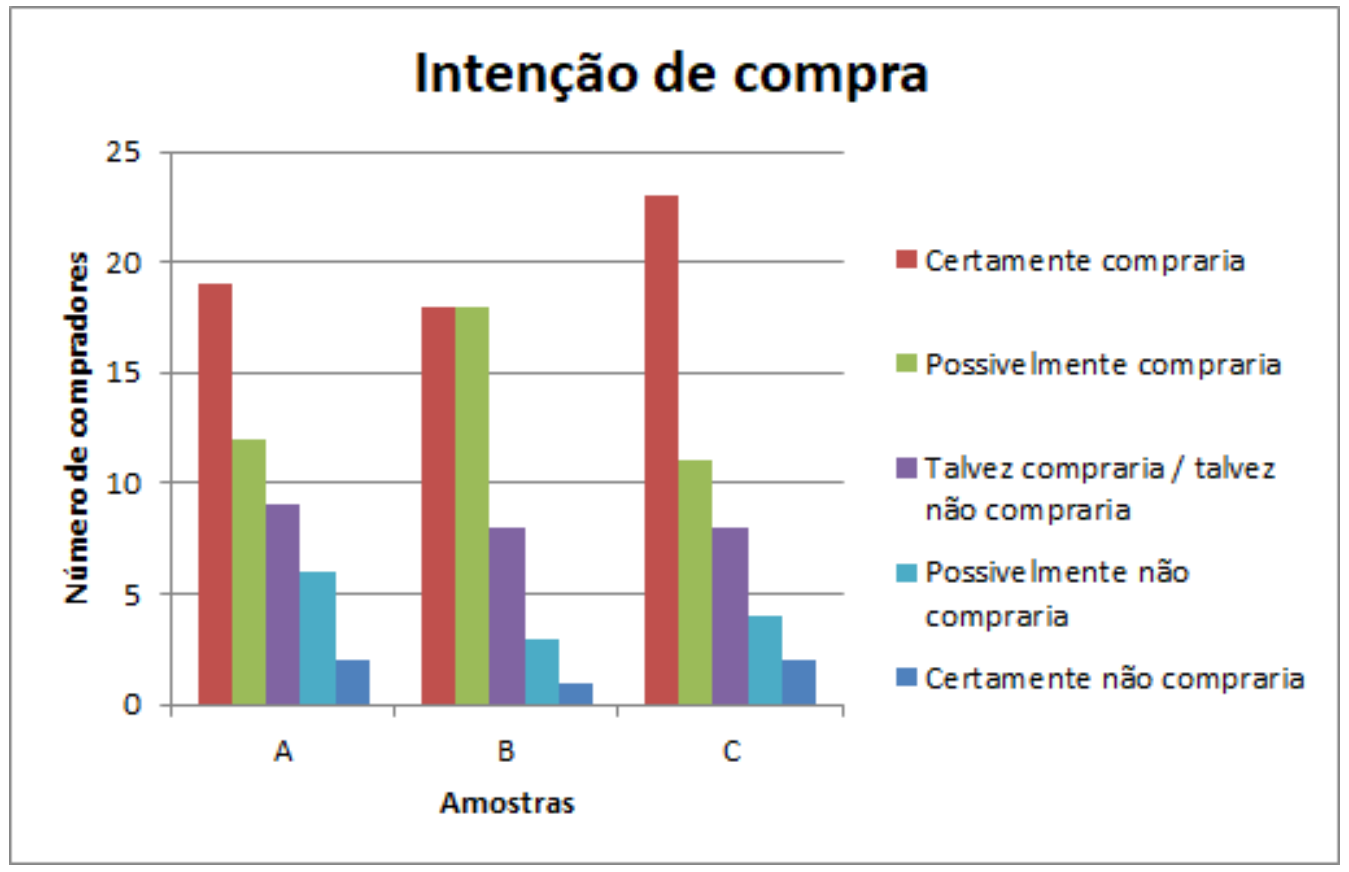

Fonte: Dos autores (2017).

\section{CONCLUSÃO}

O objetivo deste trabalho foi avaliar as características físico-químicas de pães de queijo formulados com diferentes bases, bem como a determinação de sua aceitabilidade por meio da análise sensorial e intenção de compra, na qual se observou boa aceitação. Os resultados das análises físico-químicas das massas não apresentaram expressiva variação entre as amostras. Como o pão de queijo não possui padrão de identidade e qualidade específico para o produto, os resultados obtidos não foram comparados com outras formulações.

\section{REFERÊNCIAS}

EMBRAPA. Empresa Brasileira de Pesquisa Agropecuária. Embrapa hortaliças.

Sistemas de Produção, 6, ISSN 1678-880X versão eletrônica, Jun./2008. Disponível em: <https:/ / www.embrapa.br/hortalicas/como-produzir-batata-doce>. Acesso em: 29 nov. 2017.

FUSIEGER, Rafaela. Benefícios da mandioca. UNIMED, 2017. Disponível em: <https://www.unimed.coop.br/-/beneficios-da-mandioca>. Acesso em: 22 nov. 2017. 
INMETRO. Instituto Nacional de Metrologia, Normalização e Qualidade Industrial. Portal do consumidor. Disponível em: <http:/ /www.inmetro.gov.br>. Acesso em: 10 nov. 2017.

INSTITUTO ADOLFO LUTZ. Métodos físico-químicos para análise de alimentos. 4. ed. São Paulo: Instituto Adolfo Lutz, 2008. Disponível em: <http:/ / www.crq4.org.br/ sms/files/file/analisedealimentosial_2008.pdf>. Acesso em: 08 nov. 2017.

LEONEL, Magali. Análise da forma e tamanho de grânulos de amidos de diferentes fontes botânicas. Ciência e Tecnologia de Alimentos, Campinas, v. 27, n. 3, p. 579-588, 2007. Disponível em: <http:/ / www.scielo.br/pdf/cta/v27n3/a24v27n3.pdf>. Acesso em: 22 nov. 2017.

MATTOS, Pedro L. P.; FARIAS, Alba R. N.; FILHO, José R. F. Mandioca: o produtor pergunta, a Embrapa responde. Brasília, DF : Embrapa Informação Tecnológica, 2006. 176 p. Disponível em: <https://goo.gl/JcSdi9>. Acesso em: 22 nov. 2017.

MINIM, Valéria Paula Rodrigues; MACHADO, Patricia Tanaguchi; CANAVESI, Erica; PIROZI, Monica Ribeiro. Perfil sensorial e aceitabilidade de diferentes formulações de pão de queijo. Ciênc. Tecnol. Aliment. [online]. 2000, vol.20, n.2, pp.154-159. ISSN 0101-2061. Disponível em: <http://dx.doi.org/10.1590/S0101-20612000000200005>. Acesso em: 29 nov. 2017.

NUNES, Maria Urbana Corrêa. Comportamento de cultivares de batata-inglesa (solanum tuberosum L.) em condições de baixa altitude do estado do Sergipe. Sergipe, 1996. Disponível em: <https:/ /goo.gl/zUJsgL>. Acesso em: 29 nov. 2017.

PEREIRA, Joelma et al. Função dos ingredientes na consistência da massa e nas características do pão de queijo. Ciênc. Tecnol. Aliment., Campinas, v. 24, n. 4, p. 494-500, dez. 2004. Disponível em: <http:/ /dx.doi.org/10.1590/S0101$20612004000400003>$. Acesso em: 10 nov. 2017.

PEREIRA, Joelma et al. Comparação entre a composição química determinada e a declarada na embalagem de diferentes marcas de pão de queijo. Ciênc. agrotec., Lavras, v. 29, n. 3, p. 623-628, jun. 2005. Disponível em: <http:/ /dx.doi.org/10.1590/ S1413-70542005000300017>. Acesso em: 10 nov. 2017.

RAMALHO, Maria Eduarda Oliverio; GANECO, Aline Giampietro. INTOLERÂNCIA A LACTOSE E O PROCESSAMENTO DOS PRODUTOS ZERO LACTOSE. Revista Interface Tecnológica, v. 13, n. 1, p. 15, 2016. Disponível em: <http:/ /159.203.166.88/ index.php/interfacetecnologica/article/view/130>. Acesso em: 22 nov. 2017.

SILVA, Mara Reis; GARCIA, G. K. S.; FERREIRA, H. F. Caracterização química, física e avaliação da aceitação de pão de queijo com baixo teor energético. Alimentos e Nutrição Araraquara, v. 14, n. 1, 2009. Disponível em: <http:/ / serv-bib.fcfar.unesp. br/seer/index.php/alimentos/article/viewArticle/840>. Acesso em: 22 nov. 2017. 
SHIBATA, Tania. Influência da atividade de água nas reações químicas e bioquímicas. Aqualab, 2017. Disponivel em: <http:/ /aqualab.decagon.com.br/ assets/Seminar/Atividade-de-gua-e-Reaes-bioqumicas.pdf>. Acesso em 12 dez. 2017.

TOMICH, Renata Graça Pinto et al. Metodologia para avaliação das boas práticas de fabricação em indústrias de pão de queijo. Ciênc. Tecnol. Aliment., Campinas, v. 25, n. 1, p. 115-120, Mar. 2005. Disponível em: <http:/ / www.scielo.br/scielo. php?script=sci_arttext\&pid=S0101-20612005000100019\&lng=en\&nrm=iso $>$. Acesso em: 29 nov. 2017. 